\title{
Engineering Research for Economic Advancement in Namibia
}

\author{
Nnenesi Kgabi \\ Department of Civil and Environmental Engineering, Polytechnic of Namibia, Windhoek, Namibia \\ Email: nkgabi@polytechnic.edu.na
}

Received 6 October 2014; revised 11 November 2014; accepted 25 November 2014

Copyright (C) 2014 by author and Scientific Research Publishing Inc.

This work is licensed under the Creative Commons Attribution International License (CC BY). http://creativecommons.org/licenses/by/4.0/

(c) (7) Open Access

\begin{abstract}
The aim of this special issue of the Open Journal of Applied Sciences on Engineering Research for Economic Advancement is to articulate the relevance of applied engineering research in driving the economic development and sustainability, and addressing national and regional needs of the "small economies". The research focus areas covered in this issue include renewable energy, water resources management, manufacturing systems, and sustainable mining practices. The focus areas are also relevant in addressing the global change challenges relating to sustainable production and consumption of natural resources for provision of basic services at national and local level.
\end{abstract}

\section{Keywords}

\author{
Engineering Research, Namibia, Economic Advancement, Sustainable Production and \\ Consumption
}

\section{Introduction}

Developing countries typically show poorly developed industrial sectors and, hence, are reliant on imports of basic manufactured goods; while developed countries and newly industrialized nations have managed to develop their industries within the broader spectrum of their respective development agendas. Transforming Namibia into an industrialized country of equal opportunities, which is globally competitive, is a basic goal of the country’s Vision 2030. The National Planning Commission [1] identified the country's enabling sectors (i.e. health, education, social services, water and electricity and transportation), manufacturing, agriculture and tourism as sectors expected to sustain the growth of the Namibian economy. Namibia is thus compelled to develop its industries as part of the development agenda [2].

Namibia is a sparsely populated country of approximately 2.3 million people in sub-Saharan Africa [3]. It is categorized as an upper middle-income country but has one of the highest levels of income inequality in the 
world [4] with a Gini coefficient estimated at 0.58 by the 2009/10 household survey, which is one of the highest figures of any country in the world [3]. The country has estimated annual GDP per capita of USD 5293. It was worth noting however, that from 1980-1990 Namibia had a GDP per capita which was higher than that of China and Thailand but comparable to that of Mauritius. In 2011, GDP per capita in both China and Thailand escalated much higher than that of Namibia, while Mauritius' GDP per capita rose to twice higher than that of Namibia. The country's per capita growth has been very slow compared to China, Mauritius, Thailand, Malaysia and Botswana [5].

The economy of Namibia is closely linked to that of South Africa [4] with the Namibian Dollar being pegged at a ratio of 1:1 to the South African Rand [6]. South Africa plays an important role for logistics in Namibia because it has the most developed infrastructure and logistics skills in Africa as well as functioning as a gateway for southern Africa [7]. Approximately 80\% of Namibia's total imports are from or through South Africa [4], which is claimed to exercise a great deal of pressure on Namibia through monopoly control, restrictive purchasing, over-pricing and dumping [8].

The decline in Namibia's economic competitiveness cannot be overestimated. In 2012, the Rand Merchant Bank's (RMB) ladder for the best African countries to invest in, ranked Namibia the 20th most attractive investment destination out of 53 countries, dropping one spot from RMB's 2011 overall index. Between 2007/ 2008 and 2010/2011, the country exhibited an upward trend in competitiveness rating, from 89 in 2007/2008 (out of 131), to 80 in 2008/2009 (out of 134), remaining constant in 2009/2010 and 2010/2011 (out of 133 and 139, respectively). The rating has since gone down by nine places to 83 (out of 142) in 2011/2012 and yet again by the same number to 92 in 2012/2013 (out of 144). The 2012/2013 ranking is the lowest the country has been ranked over the years [9]. The country intends to reverse this trend by pursuing long and short term goals as articulated in Vision 2030 and recently through NDP-4 and other sectoral interventions. Some of the long term interventions include increased investment in education and training, health sector, infrastructure, and Broad based incentive strategy [5].

The role of engineering research focused at economic advancement is thus a necessity for the country, and should without fail affect the technological imports and exports. The World Bank [10] confirmed that Namibia's technology-intensive exports were very small as a proportion of total merchandise exports. Low-, medium-, and high-technology exports together accounted for just 9 percent of total merchandise exports in 2008. Namibia's technology imports are dominated by medium-technology (mainly transport equipment, machinery, and chemical products) and high-technology goods (mainly machinery and pharmaceutical products), which account for 29 percent and 15 percent, respectively, of Namibia's total merchandise [10]. The need for technological change, which raises the relative marginal productivity of capital through education and training of the labor force, investments in research and development and the creation of new managerial structures and work organization, is thus evident. Analytical work on long-term economic growth shows that in the 20th century the factor of production growing most rapidly has been human capital, but there are no signs that this has reduced the rate of return to investment in education and training [11].

The state of research and development in Namibia has been described by Kgabi [12] as more subject specific rather than multidisciplinary, while the current emphasis worldwide is on interdisciplinary, multidisciplinary, and trans-disciplinary approaches with increasing focus on problems, rather than techniques; and more emphasis on collaborative work and communication. The National Planning Commission [1] however, purports that the ability of the country to perform applied research in critical areas such as agriculture, fisheries, geology, information technology and manufacturing is severely hampered by the lack of qualified graduates in engineering, biology, chemistry, mathematics and information technology [1]. This in a way keeps the knowledge economy and hence the pace of technological advancement of the country at its lowest. Powell and Snellman [13] define knowledge economy as production and services based on knowledge-intensive activities that contribute to an accelerated pace of technical and scientific advance, as well as rapid obsolescence. The key component of a knowledge economy is thus a greater reliance on intellectual capabilities than on physical inputs or natural resources. The concept of knowledge economy, which can only be developed by strengthening applied research, is crucial to a country like Namibia, which is aspiring expansion and emergence of new industries.

Contribution by Namibian institutions of higher learning in the form of development of engineering and applied sciences research is increasingly being recognized. Despite the fact that the higher education sector faces the challenges of recruiting and retaining Namibians who hold post graduate level qualifications; which is particularly true for the sciences, ICTs and engineering where most of the research and innovation output is ex- 
pected [1]; this special issue covers some of the research activities carried out by researchers in the School of Engineering, Polytechnic of Namibia. According to John [14], the research focus areas of the School of Engineering (SoE) were carefully chosen to respond to Namibian national imperatives as presented in the National Development Plans (NDPs), and the National Vision 2030. Global trends and in-house capacity, coupled with support from numerous national and international partners inform the SoE broad research fields, which are: Renewable energy which focuses on the development, analysis, design and implementation of renewable energy systems and technologies; Water resources management aimed at developing efficient ways of generating, distributing and re-using water resources; Manufacturing systems aimed at supporting the manufacturing sector of the nation through research activities in the fields of mechatronics, control systems and appropriate technology developments; and Sustainable mining practices with risk and safety management and environmental issues as a focus area for research activities in the mining sector [14].

It might be advisable though, to "pick" and implement President Barack Obama's ideas captured by the National Science Board of the United States of America, i.e. "We need to build a future in which our factories and workers are busy manufacturing the high-tech products that will define the century... Doing that starts with continuing investment in the basic science and engineering research and technology development from which new products, new businesses, and even new industries are formed”-President Barack Obama, February 2012 [15].

\section{References}

[1] National Planning Commission (NPC) (2012) Republic of Namibia, National Human Resources Plan 2010-2025, October 2012.

[2] (2012) Republic of Namibia, Namibia’s Fourth National Development Plan (NDP4) 2012/13 to 2016/17, Windhoek, May 2012.

[3] World Bank (2013) World Development Indicators. http://data.worldbank.org/country/namibia

[4] African Development Bank (2007) African Economic Outlook: Namibia. AIBD, Abidjan.

[5] National Planning Commission (NPC) (2012) Annual Economic Development Report 12.

[6] World Bank (2009) Namibia Country Brief. http://site.ebray.com/lib/uoh

[7] Cilliers, W. and Nagel, P. (1994) Logistics Trends in South Africa. International Journal of Physical Distribution \& Logistics Management, 24, 4-14. http://dx.doi.org/10.1108/09600039410070948

[8] Clerck, G. (2008) Industrial Relation in Namibia Since Independence: Between Neo-Liberalism and Neo-Corporatism? Employee Relations, 30, 355-371. http://dx.doi.org/10.1108/01425450810879349

[9] World Economic Forum (2014) http://www.weforum.org/reports/

[10] World Bank (2011) Fostering Technology Absorption in Southern African Enterprises, Directions in DevelopmentPrivate Sector Development.

[11] Organisation for Economic Co-operation and Development (OECD) (1996) The Knowledge-Based Economy, General Distribution. OCDE/GD(96)102, Paris.

[12] Kgabi, N. (2011) The Current State of Research Development in Namibia. PROGRESS Multidisciplinary Research Journal, 1.

[13] Powell, W.W. and Snellman, K. (2004) The Knowledge Economy. Annual Review of Sociology, 30, 199-220. http://dx.doi.org/10.1146/annurev.soc.29.010202.100037

[14] John, S. (2014) Research within the School of Engineering, School of Engineering Research Day 2014, Programme and Abstracts Book. Polytechnic of Namibia, 18 July 2014, 4.

[15] National Science Board (NSB) (2012) Research \& Development, Innovation and the Science and Engineering Workforce. A Companion to Science and Engineering Indicators 2012. National Science Foundation (NSB-12-03), Arlington. 
Scientific Research Publishing (SCIRP) is one of the largest Open Access journal publishers. It is currently publishing more than 200 open access, online, peer-reviewed journals covering a wide range of academic disciplines. SCIRP serves the worldwide academic communities and contributes to the progress and application of science with its publication.

Other selected journals from SCIRP are listed as below. Submit your manuscript to us via either submit@scirp.org or Online Submission Portal.
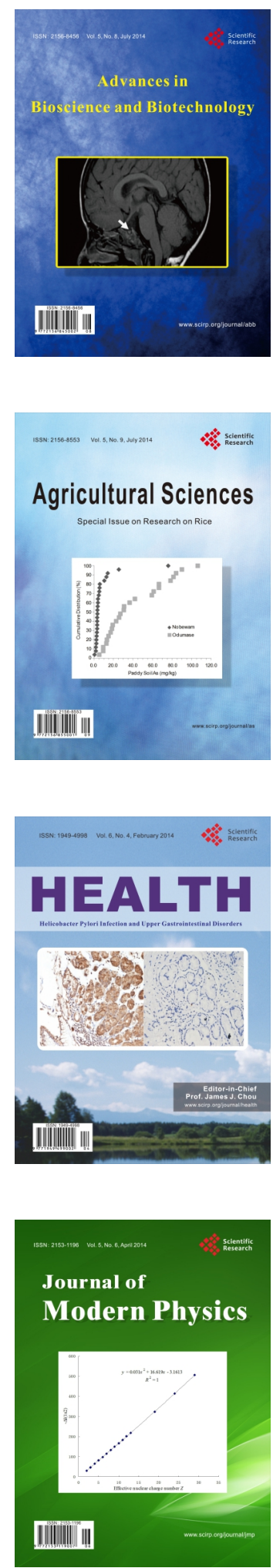
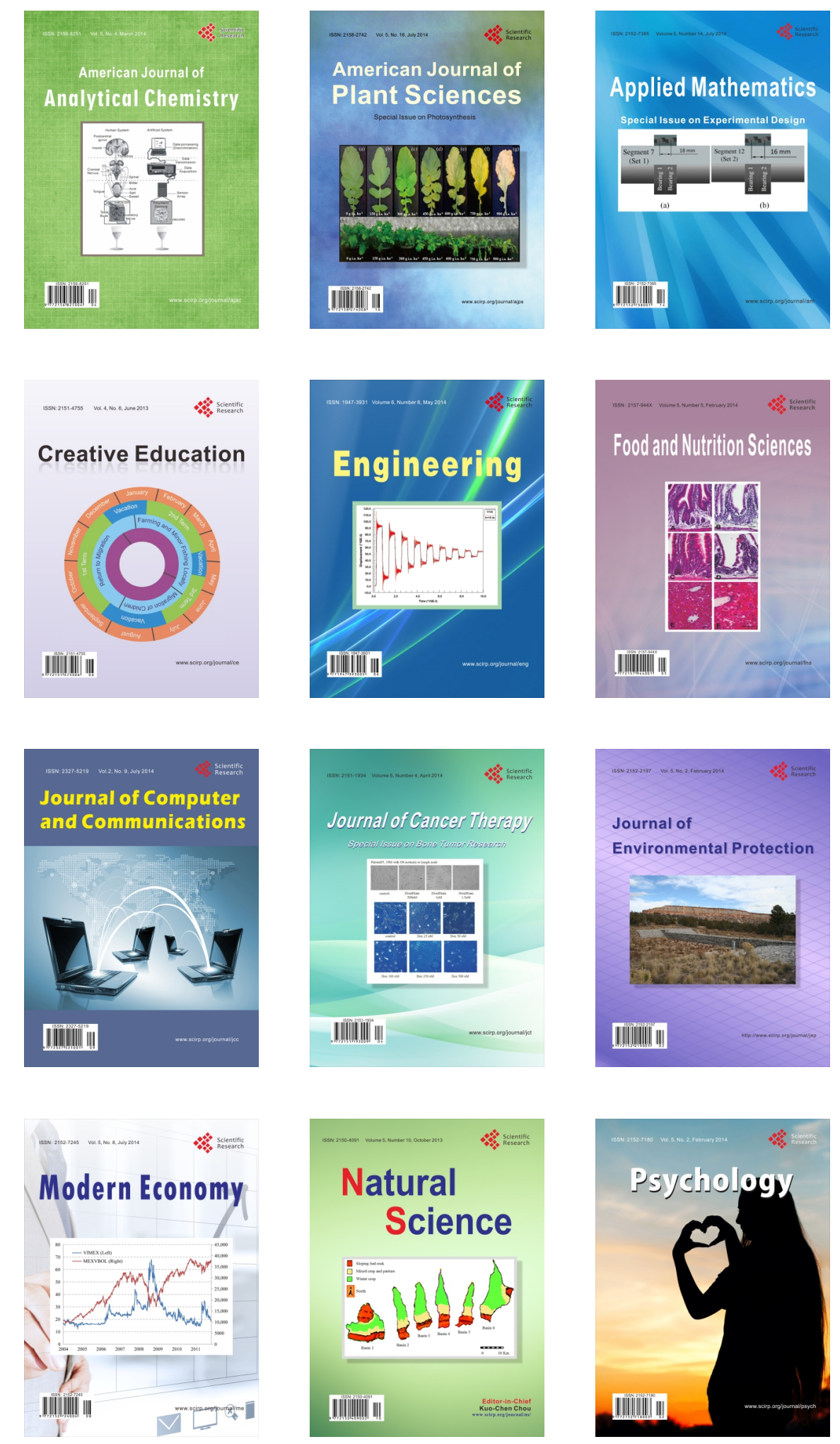